\title{
AUXILIARES DE ENFERMAGEM: MERCADO DE TRABALHO, PERFIL, SATISFAÇÃO E EXPECTATIVAS NO PROGRAMA DE SAÚDE DA FAMÍLIA NA CIDADE DE SÃO PAULO
}

\author{
NURSING ASSISTANTS: JOB MARKET, PROFILE OF PROFESSIONALS, SATISFACTION AND \\ EXPECTATIONS IN THE FAMILY HEALTH PROGRAM OF THE CITY OF SÃO PAULO.
}

\author{
Regina Maria Giffoni Marsiglia ${ }^{1}$
}

Resumo São escassos os estudos sobre os auxiliares de enfermagem, mesmo nas equipes de saúde da família. Este artigo se baseia em estudo que procurou identificar o perfil dos auxiliares de enfermagem do Programa de Saúde da Família (PSF) na Região Metropolitana de São Paulo, o grau de satisfação com o trabalho, sugestões para melhorar o PSF e expectativas quanto ao futuro profissional. Em 2004, o Departamento de Atenção Primária à Saúde e Programa de Saúde da Família da Secretaria Municipal de Saúde da Cidade de São Paulo, aplicou um questionário entre os integrantes das equipes implantadas no município. A análise das respostas de 901 auxiliares de enfermagem contou com o apoio da Unesco. Os principais resultados apresentados neste artigo são: predominância de mulheres, jovens, nível médio de escolarização; capacitação inicial para o PSF, baixa proporção de profissionais com nível técnico. As relações e o processo de trabalho constituem motivos de maior satisfação e as condições de trabalho são pouco satisfatórias. Razões mais citadas para a escolha da profissão, solidariedade e cuidado com o 'próximo'; para a inserção no PSF, nova alternativa no mercado de trabalho e reconhecimento da sociedade. A maioria pretende continuar sua formação, com graduação em Enfermagem e especialização em Saúde Pública ou Saúde da Família².

Palavras-chave auxiliar de enfermagem; perfil social no Programa de Saúde da Família; formação; expectativas profissionais.
Abstract Studies on nursing assistants are rare, even on nursing assistants in family health teams. The article is based on a study that intended to determine the profile of Nursing Assistants in the Family Health Program in the Metropolitan Area of São Paulo, to identify their level of satisfaction with work, to seek suggestions for improving the Family Health Program, and to assess their expectations as to their professional future. In 2004, the Department of Primary Health Care and Family Health Program of the Municipal Health Secretariat of São Paulo sent out a questionnaire to the members of the city's teams. The analysis of the answers of 901 nursing assistants received support from Unesco. The major results presented in this article are the predominance of women, young individuals and individuals only with secondary school education in the teams; most of whom had been through basic training for the Family Health Program; and only a small number of whom had completed technical courses. Nurses are satisfied with work relations and work processes, but dissatisfied with work conditions. The most mentioned reasons for having chosen the profession were solidarity and the care for other people. On the other hand, the reasons for having entered the Family Health Program were the fact that it was an alternative in the job market and because of society's appreciation of the field. Most of them intend to continue training, later completing undergraduation in Nursing and specializing in Public Health or Family Health.

Key words nursing assistant; social profile of the Family Health Program; training; professionals expectations. 


\section{Introdução}

Os estudos sobre os recursos humanos na área de saúde são de interesse comum entre gestores dos serviços, pesquisadores, formadores de profissionais e trabalhadores de saúde.

Nas duas últimas décadas, trabalhos foram produzidos, a partir de diferentes abordagens, utilizando-se de diferentes perspectivas metodológicas e instrumentos de coleta de informações, demonstrando que há acúmulo de conhecimentos e produção sobre o tema.

O mesmo ocorre com as experiências do Programa de Saúde da Família (PSF), que, embora definido e implantado oficialmente no país a partir de 1995, já contabiliza uma série de trabalhos produzidos nos serviços de saúde e também na academia. Particular importância adquiriu nos últimos anos a preocupação com os recursos humanos no PSF, diante da inexistência de profissionais da área de saúde, em número e com perfil adequados, para o exercício das funções e tarefas que lhes são exigidas, fato que, ao final dos anos 1990, incentivou as administrações estaduais e federal a implantarem, em ação conjunta com as instituições de ensino, os Pólos de Formação, Capacitação e Educação Continuada de Profissionais para Saúde da Família.

No entanto, muito embora a categoria auxiliar de enfermagem integre a equipe de enfermagem e participe de todos os programas de atenção à saúde, em todos os níveis de complexidade, os estudos sobre ela são pouco numerosos, e até ausentes, em determinadas linhas de análise que abordam a questão dos recursos humanos em saúde.

Nos estudos sociológicos sobre as profissões, como os auxiliares de enfermagem não apresentam as características essenciais de uma profissão (base técnica com monopólio de competências, autonomia profissional e código de ética próprio), mas as 'emprestam' da profissão de enfermagem, podemos dizer que a categoria constitui mais uma ocupação na divisão sócio-técnica do trabalho de enfermagem do que uma profissão propriamente dita.

Analisando o trabalho em saúde, Agudelo (1995) aponta para sua divisão técnica em dois sentidos: no sentido horizontal, como ocorre na profissão médica, na perspectiva da especialização, e no sentido vertical, como na enfermagem, com a redistribuição hierárquica das tarefas entre trabalhadores de diferentes níveis de qualificação: enfermeiros, técnicos, auxiliares e atendentes. Mas no Brasil, com as exigências da lei $n^{\circ} 7.498 / 86^{3}$ para a qualificação dos atendentes de enfermagem, este segmento deixou de existir oficialmente na metade da década de 1990.

A Lei de Diretrizes e Bases da Educação Nacional (LDB) de 1996 definiu as exigências e qualificações da educação básica e da educação profissional e a articulação necessária entre ambas ${ }^{4}$. Como nas demais ocupações técnicas de nível médio, os auxiliares de enfermagem desenvolvem habilidades pou- 
co especializadas e apresentam uma formação insuficiente para enfrentar as necessidades do trabalho em saúde. Diante das novas exigências da LDB para a educação profissional, a resolução $n^{\circ}$ 278/03 do Conselho Federal de Enfermagem (Cofen) regulou a Concessão de Inscrição Provisória do Auxiliar de Enfermagem, como itinerário do Curso de Educação Profissional de Técnico de Enfermagem, com um prazo máximo de validade de cinco anos (Otaviano, 2005).

As inovações do trabalho em saúde, ao mesmo tempo em que permitem a melhoria da qualidade e da produtividade dos serviços, exigem maior escolaridade, flexibilidade e novas competências para os trabalhadores, inclusive para os auxiliares de enfermagem. É necessário um novo tipo de trabalhador que

“(...) seja capaz de compreender e participar de um ambiente em que as decisões são mais complexas e as interações sociais mais numerosas. Qualidades como capacidade de trabalhar com os outros e administrar conflitos, tornam-se cada vez mais importantes" (Otaviano, 2005, p. 93).

Os estudos sobre recursos humanos, na perspectiva do mercado de trabalho, tornaram-se freqüentes no Brasil a partir dos anos 1980, ressaltando-se a dimensão e a complexidade desse mercado. Em 1986, o mercado de trabalho em saúde já absorvia $8 \%$ do total de empregos existentes na economia formal do país, e o contingente de nível médio e elementar foi o mais requisitado (Sinais, 2001).

Pierantoni (2002) confirma a manutenção desta tendência nos anos 1990: o mercado de trabalho formal do setor saúde já absorvia 2,15 milhões de empregos, o que representava $9 \%$ dos postos de trabalho na economia formal do país, continuando a crescer ao final da década de 1990 e início dos anos 2000, apesar da retração de outros setores da atividade econômica. Ressalta ainda a autora que, além de profissionais de saúde e trabalhadores diretamente envolvidos na atenção à saúde, o setor incorpora uma massa de trabalhadores sem formação específica para a área, no preenchimento de funções auxiliares administrativas e de apoio na prestação dos serviços de saúde.

Especificamente no que se refere à categoria dos auxiliares de enfermagem, o censo realizado pelo Cofen e pela Associação Brasileira de Enfermagem (ABEn) referente ao período 1982-1983 concluiu que existiam na época 64.289 auxiliares de enfermagem, 25.889 enfermeiros, 19.935 técnicos de enfermagem e 194.174 atendentes de enfermagem.

Posteriormente, os trabalhos de Girardi e Carvalho (2002) apontaram que, entre 1995 e 2000, houve uma taxa de incremento bruto de 22,1\% nos vínculos de emprego de auxiliares de enfermagem: em 1995, eles eram 199.899 empregados, correspondendo a $24,5 \%$ do mercado dos profissio- 
nais de saúde, passando para 314.233 em 2000, o que correspondia a 33,8\% deste mercado. Configura-se, então, uma taxa de incremento dos vínculos de emprego no setor acima da média de todo o pessoal de saúde no período, que foi de 13,9\%.

Esse crescimento pode ser explicado, em parte, pelos esforços de capacitação dos atendentes de enfermagem para atuar como auxiliares de enfermagem, já que no mesmo período estes apresentaram uma taxa negativa de incremento bruto (passaram de 126.616 para 68.609 empregados). Mas também pelo uso do subterfúgio dos serviços de saúde de não registrar adequadamente os atendentes, passando-os para uma relação informal de emprego ou registrando-os em outras funções, como auxiliares de serviços gerais ou 'braçais', para fugir da fiscalização do Cofen a partir de 1996 (Sinais, 2001, p. 8).

Dados dos Ministérios do Trabalho e Emprego indicam que 60,10\% dos empregos dos auxiliares de enfermagem ocorriam em organizações do setor privado e $39,90 \%$, em organizações do setor público. No interior do setor público, 1,38\% estavam empregados no nível federal, 11,90\% no estadual, $18,84 \%$ no municipal e 7,78\% em outras formas de organização da administração pública. Já no setor privado, 26,57\% estavam empregados em empresas e 32,97\% em instituições privadas sem fins lucrativos (MTE, 1996a e 1996b).

Girardi e Carvalho (2002) demonstram que a situação do emprego dos auxiliares de enfermagem entre 1995 e 2000 apresentou maior incremento no setor privado, especialmente no privado não lucrativo: em 2000, 107.358 empregos para auxiliares de enfermagem estavam nos serviços públicos de saúde, 90.508 nos privados lucrativos e 115.211 nos privados não lucrativos, totalizando 313.077 empregos para a categoria.

No interior do setor público podemos afirmar que houve uma descentralização do emprego, especialmente em direção ao nível municipal: no nível federal, em 1995, estavam 7,3\% dos empregos de auxiliares de enfermagem, caindo este percentual para 1,5\% em 2000. Já no nível estadual, que em 1995 detinha $32,8 \%$ dos empregos de auxiliares de enfermagem, houve um pequeno incremento em 2000, chegando a 35,8\%. No nível municipal é que se percebe maior descentralização ou migração dos empregos da categoria - passou, em 2000, a ofertar 61,8\% dos empregos do mercado de trabalho dos auxiliares de enfermagem, contra os 45,9\% que ofertava em 1995. Consideram os autores, ainda, que nesse período (1995-2000) pode ter havido uma certa 'desospitalização' do emprego dos profissionais de saúde, o mesmo devendo ocorrer com os auxiliares de enfermagem (Girardi e Carvalho, 2002).

Uma das questões a serem investigadas é o impacto dos empregos gerados pelo PSF e a ampliação da assistência de nível ambulatorial. Por outro lado, no período 1990-1995, houve um crescimento do emprego no vínculo estatutário superior a $20 \%$ ao ano, no caso dos auxiliares de enfermagem, 
mas, no período 1995-2000, houve uma discreta inversão da tendência, com crescimento maior dos vínculos celetistas.

Quanto à escolaridade, estudo do Profae - Programa de Profissionalização dos Trabalhadores da Área de Enfermagem 5 (Sinais, 2001) demonstra com dados de 1997-1998 a tendência dos empregadores da saúde, especialmente do setor privado, para a contratação de pessoal de maior escolaridade, especialmente com segundo grau completo, atual nível médio.

\footnotetext{
“Maiores oportunidades de emprego no segmento celetista do mercado de trabalho parecem assim estar reservadas aos trabalhadores com maior escolaridade, ao passo que se tornam mais escassas as oportunidades de emprego para trabalhadores menos escolarizados. Essa tendência, ao que parece, se acentua no decorrer dos anos 90" (Sinais, 2001, p. 56).
}

O mesmo estudo do Profae informa que, em 1996, havia 221.616 empregos de auxiliares de enfermagem (incluindo-se 2.661 auxiliares de enfermagem do trabalho): 54,2\% na região Sudeste e 32,0\% no Estado de São Paulo (Sinais, 2001).

Concentrando a atenção sobre os auxiliares de enfermagem no Estado de São Paulo, pesquisa de Moura et al. (1996) para o Conselho Regional de Enfermagem de São Paulo (Coren/SP) e para a ABEn/SP aponta que a categoria auxiliar de enfermagem cresceu 26,0\% entre 1983 e 1996; houve um aumento desses profissionais na faixa etária de 25 a 35 anos; entre os auxiliares de enfermagem estava o maior contingente de trabalhadores do sexo masculino na saúde; 44,4\% trabalhava entre 37 e 40 horas nas instituições pesquisadas e $32,0 \%$, entre 31 e 36 horas semanais. Isto sem considerar que $24 \%$ do pessoal de enfermagem trabalhava em mais de um emprego. Observou-se ainda uma certa estabilidade no emprego, já que nos últimos cinco anos $76,5 \%$ tinham se mantido no mesmo emprego; o maior contingente de auxiliares de enfermagem, 34,38\%, trabalhava em clínica médica e cirúrgica, seguidos por hemodinâmica/unidades de transplante $(25,46 \%)$, centros cirúrgicos e central de material $(8,46 \%)$, centro obstétrico, obstetrícia e neonatologia $(8,28 \%)$, saúde pública $(7,69)$, ambulatórios e diagnóstico por triagem $(6,16)$ e pediatria $(6,13 \%)$.

\section{Auxiliares de enfermagem no PSF}

Os estudos sobre os profissionais que participam das equipes de saúde da família, em sua maioria, concentram-se nos médicos e enfermeiros (Machado, 2000) ou nos agentes comunitários de saúde (Silva e Dalmaso, 2002a e 2002b; Bernardino et al., 2005), enquanto os auxiliares de enfermagem são 
pouco contemplados. Pierantoni (2002) registra que, em 2002, havia 19.706 auxiliares de enfermagem participando de 15.523 equipes de saúde da família, distribuídas por 4.709 municípios do país. Esta observação nos leva a considerar que mais de dois terços das equipes eram compostas por um único auxiliar de enfermagem.

O documento do Ministério da Saúde que apresentou os princípios do PSF e sua organização (MS, 1997) incluiu o auxiliar de enfermagem na equipe mínima do PSF, mas não especificou o número de profissionais que cada equipe deveria ter. Definiu as ações que o profissional deveria desenvolver na unidade de saúde, no domicílio e na comunidade, sendo suas atribuições:

“(...) desenvolver, com os Agentes Comunitários de Saúde, atividades de identificação das famílias de risco; contribuir, quando solicitado, com o trabalho dos ACS, no que se refere às visitas domiciliares; acompanhar as consultas de enfermagem dos indivíduos expostos às situações de risco, visando a garantir uma melhor monitoria de suas condições de saúde; executar, segundo sua qualificação profissional, os procedimentos de vigilância sanitária e epidemiológica nas áreas de atenção à criança, à mulher, ao adolescente, ao trabalhador e ao idoso, bem como no controle da tuberculose, hanseníase, doenças crônico-degenerativas e infecto-contagiosas; participar da discussão e organização do processo de trabalho da unidade de saúde" (MS, 1997, p. 17).

Chiesa et al. (2001) elaboraram uma proposta de capacitação específica para os auxiliares de enfermagem que compunham as equipes no município de São Paulo ${ }^{6}$ para ser desenvolvida após o Módulo de Introdução ao PSF, que é ministrado a todos os profissionais que compõem as equipes. $\mathrm{Na}$ ocasião, a equipe encarregada da elaboração da proposta constatou que não havia acúmulo de discussão sobre o papel profissional desta categoria no programa, bem como eram poucas as experiências de capacitação dirigidas especificamente para os auxiliares de enfermagem, havendo apenas treinamentos pontuais em serviço e execução de procedimentos técnicos de enfermagem nas unidades de saúde da família.

A intenção expressa pelo grupo de trabalho foi

“(...) apresentar uma proposta de curso que ampliasse e valorizasse o papel profissional do Auxiliar de Enfermagem e sua inserção na Equipe de Saúde da Família, e que caminhasse na perspectiva do desenvolvimento de ações promocionais de saúde, dentro e fora da Unidade de Saúde da Família" (Chiesa et al. 2001, p. 4). 
A proposta vinha ao encontro da necessidade de se desenvolverem outras competências ${ }^{7}$ para uma categoria profissional habituada a procedimentos técnicos, mais voltados para os serviços hospitalares e com menor experiência em saúde pública, como confirmam as informações apresentadas anteriormente sobre o mercado de trabalho da categoria.

Por outro lado, reconhecia-se a pouca ênfase que vinha sendo dada às atribuições e à formação dos auxiliares de enfermagem para o trabalho no PSF: este exige novos conhecimentos e uma revisão da prática profissional; inserção em novos processos de trabalho; novas relações entre os profissionais, e entre estes e as famílias atendidas e a população da área adscrita; criação de vínculos e responsabilidades coletivas na ampliação do acesso aos serviços de saúde como garantia dos direitos de cidadania no país8.

Além da escassez de estudos sobre os auxiliares de enfermagem no PSF, é importante considerar que as pesquisas sobre o desenvolvimento do próprio programa nas grandes cidades, como é o caso da área metropolitana da cidade de São Paulo, também são recentes 9 .

Diante dos fatos expostos, em 2004 o Departamento de Atenção Básica à Saúde e Programa de Saúde da Família da Secretaria Municipal de Saúde de São Paulo (SMS/SP) realizou um levantamento com os trabalhadores do PSF visando a orientar futuros processos de capacitação, aprimorar o trabalho e, particularmente no caso dos agentes comunitários de saúde, conhecer a situação educacional deste contingente.

Na ocasião havia no município 670 equipes de saúde da família e 114 equipes de agentes comunitários de saúde, totalizando 668 médicos, 792 enfermeiros, 1.448 auxiliares de enfermagem e 4.688 agentes comunitários de saúde.

As equipes haviam sido implantadas, a partir de 2001, em 186 unidades básicas de saúde, distribuídas nas cinco Coordenadorias Regionais de Saúde (Norte, Leste, Centro-Oeste, Sudeste, e Sul), e os profissionais, contratados por doze parceiras da SMS/SP: Casa de Saúde Santa Marcelina, Associação Saúde da Família, Associação Congregação Santa Catarina, Universidade Federal de São Paulo (Unifesp), Fundação Zerbini, Centro de Estudos e Pesquisas Dr. João Amorim (Cejam), Associação Comunitária Monte Azul, Fundação Faculdade de Medicina da Universidade de São Paulo (USP), Organização Santamarense de Educação e Cultura (Unisa), Instituto Adventista de Ensino, Hospital Israelita Albert Einstein e Irmandade da Santa Casa de São Paulo.

Questionários foram distribuídos no início de eventos coletivos e recolhidos ao final. Foram preenchidos por 4.752 trabalhadores do PSF do município de São Paulo, dentre os quais 901 eram auxiliares de enfermagem, o que representava $62,2 \%$ dos auxiliares que integravam as equipes de saúde da família naquele momento. 


\section{Instrumento utilizado}

O questionário, com 45 perguntas a serem respondidas por todos os trabalhadores do PSF era bastante complexo: 22 perguntas fechadas para caracterizar o perfil e a formação dos participantes; 17 afirmações para medir a satisfação do entrevistado com seu trabalho, construindo uma escala de Likert ${ }^{10}$ (Quadro 1); e seis questões abertas que exploravam os pontos positivos e negativos do trabalho no PSF, na opinião do próprio trabalhador - que sugestões tinham para o programa, quais eram as razões de suas escolhas profissionais e pelo PSF e os planos para o seu futuro profissional (Quadro 2).

\section{Quadro 1}

Escala de satisfação com o trabalho no PSF; questões e indicadores

\begin{tabular}{|c|c|c|}
\hline Item & Questão & Indicador \\
\hline 5.1 & Faço aquilo que gosto. & Identidade com a tarefa \\
\hline 5.2 & $\begin{array}{l}\text { O treinamento que recebo é suficiente para realizar } \\
\text { meu trabalho no PSF. }\end{array}$ & Treinamento \\
\hline 5.3 & O ambiente físico da unidade dificulta meu trabalho. & Ambiente físico \\
\hline 5.4 & Disponho de materiais para realizar meu trabalho. & Materiais \\
\hline 5.5 & Sinto muita tensão no trabalho. & Estresse \\
\hline 5.6 & No PSF, meu potencial e minhas experiências são utilizados. & Uso de habilidades \\
\hline 5.7 & $\begin{array}{l}\text { O trabalho no PSF permite que eu melhore } \\
\text { meus conhecimentos. }\end{array}$ & Crescimento no trabalho \\
\hline 5.8 & $\begin{array}{l}\text { Considero que os serviços de minha equipe do PSF } \\
\text { possuem qualidade. }\end{array}$ & Qualidade do serviço no setor \\
\hline 5.9 & Na minha equipe do PSF o paciente é bem atendido. & Qualidade do atendimento no PSF \\
\hline 5.10 & $\begin{array}{l}\text { Os profissionais da equipe do PSF podem discutir as } \\
\text { dificuldades encontradas no trabalho. }\end{array}$ & Confiança nas relações de equipe \\
\hline 5.11 & Me dou bem com meus colegas de equipe de PSF & Relacionamento intra-equipe \\
\hline 5.12 & Minha equipe do PSF realiza reuniões com regularidade. & Reuniões de equipe \\
\hline 5.13 & $\begin{array}{l}\text { Minha Unidade Básica de Saúde realiza reuniões } \\
\text { com regularidade. }\end{array}$ & Reuniões da unidade \\
\hline 5.14 & Pretendo trabalhar por longo tempo no PSF. & Adesão \\
\hline 5.15 & Meu trabalho é valorizado pela comunidade. & Imagem externa \\
\hline 5.16 & $\begin{array}{l}\text { Acredito que os resultados dessa pesquisa serão } \\
\text { bem utilizados. }\end{array}$ & Credibilidade da pesquisa \\
\hline 5.17 & $\begin{array}{l}\text { É muito difícil participar da equipe de saúde e ser } \\
\text { membro da comunidade ao mesmo tempo. }\end{array}$ & Interface equipe/comunidade \\
\hline
\end{tabular}

Fonte: Coordenação de Atenção Básica e Programa de Saúde da Família - SMS/SP 


\begin{tabular}{ll}
\hline Satisfação e insatisfação, razões para escolha da profissão e do PSF e expectativas profissionais \\
\hline Item & Questão \\
\hline 6.1 & O que lhe traz mais satisfação no trabalho? (cite até três) \\
6.2 & O que Ihe traz insatisfação no trabalho? (cite até três) \\
6.3 & O que fez você escolher sua profissão? \\
6.4 & Por que você veio trabalhar no PSF? \\
6.5 & Quais são os seus planos para seu futuro profissional? \\
6.6 & Quais são as suas sugestões para o PSF?
\end{tabular}

Fonte: Coordenação de Atenção Básica e Programa de Saúde da Família - SMS/SP

\section{Apresentação dos resultados}

No que diz respeito aos auxiliares de enfermagem, verificou-se que $91,3 \%$ da categoria profissional pertencem ao sexo feminino; 26,4\% têm entre 21 e 29 anos, 28,7\%, entre 30 e 39, e 28,2\%, entre 40 e 49 . Metade deles é formalmente casado, outros $12,0 \%$ são divorciados e $6,8 \%$ vivem em união consensual, enquanto $28,6 \%$ são solteiros; $49,2 \%$ têm um ou dois filhos, $24,1 \%$, entre três e quatro filhos e $23,6 \%$ informaram não ter filhos ${ }^{11}$.

A maioria dos entrevistados, isto é, 59,6\%, nasceram no próprio município de São Paulo, 27,6\% em outros Estados do país e 12,7\% em outros municípios do Estado de São Paulo. Em termos de escolaridade, alguns desses profissionais apresentaram formação acima do nível exigido no momento para o exercício de sua função, uma vez que 3,2\% possuem formação de nível superior. Constatou-se também que 60,2\% cursaram até a terceira série do nível médio, $34,8 \%$ até a segunda e 5,0\% até a primeira, o que mostra o não cumprimento das exigências do Cofen (resolução no 276/03), já que apenas $40,1 \%$ possuem formação de nível técnico.

A maioria desses auxiliares de enfermagem trabalhava há pouco tempo no programa: 52,7\% entre um e dois anos, 25,8\% entre três e quatro anos e $8,7 \%$ há menos de um ano, coincidindo o tempo máximo de trabalho de quatro anos com a municipalização dos serviços de saúde na cidade de São Paulo.

A maioria deles $(87,2 \%)$ não trabalha ou não trabalhou em outras unidades do PSF e $87,4 \%$ só possuíam este vínculo de trabalho. Considerando-se a possibilidade de múltipla escolha, observamos que dentre os que responderam ter tido experiências profissionais anteriores, 4,9\% havia trabalhado em hospitais, 46,1\% em postos de saúde, 33,7\% em outros serviços ligados à saúde e 26,7\% em trabalhos não relacionados à área de saúde.

Quanto à capacitação específica para o trabalho no PSF, 75,6\% dos auxiliares de enfermagem cursaram o Momento I, Módulo Introdutório; 
41,6\% participaram de outros cursos; $26,8 \%$ cursaram o Momento II, Ciclo de Vida; e 5,3\% não freqüentaram nenhum curso que os preparasse para trabalhar no programa.

A forma majoritária de contratação dos auxiliares de enfermagem para o PSF pelas instituições parceiras deu-se através do regime da CLT (77,0\%), contra $22,5 \%$ que referem ser funcionários públicos, no regime estatutário, recebendo complementação via CLT, através da instituição parceira.

\section{Satisfação e percepções sobre o trabalho no PSF}

Partindo da Escala de Likert, podemos verificar as afirmações que receberam dos auxiliares de enfermagem do PSF maior aprovação/satisfação e as que receberam menor aprovação/insatisfação (Quadro 3). Os indicadores que apresentam percentuais mais favoráveis, isto é, como os quais mais de $90 \%$ dos auxiliares estão satisfeitos, são: adesão ao PSF $(95,6 \%)$, relacionamento intra-equipe $(95,5 \%)$, identidade com a tarefa $(95,3 \%)$, reuniões de equipe $(92,1 \%)$ e qualidade do atendimento $(90,4 \%)$.

Por outro lado, os indicadores relacionados às condições de trabalho apresentam os menores percentuais favoráveis: ambiente físico (42,6\%), seguido de estresse no trabalho $(47,1 \%)$, falta de material $(60,3 \%)$ e treinamento insuficiente para o desenvolvimento das tarefas $(67,4 \%)$. 
Satisfação do trabalho entre auxiliares de enfermagem do PSF no município de São Paulo (2004)

\begin{tabular}{|c|c|c|c|c|c|c|c|c|c|}
\hline Item & Questão & Indicador & $\begin{array}{l}\text { Totalmente } \\
\text { insatisfeito }\end{array}$ & $\begin{array}{l}\text { Parcialmente } \\
\text { insatisfeito }\end{array}$ & $\begin{array}{l}\text { Nem satisfeito, } \\
\text { nem insatisfeito }\end{array}$ & $\begin{array}{l}\text { Parcialmente } \\
\text { satisfeito }\end{array}$ & $\begin{array}{l}\text { Parcialmente } \\
\text { favorável }\end{array}$ & $\begin{array}{c}\text { Totalmente } \\
\text { satisfeito }\end{array}$ & $\begin{array}{c}\text { No de respostas } \\
\text { vallidas }\end{array}$ \\
\hline 5.14 & $\begin{array}{l}\text { Pretendo trabalhar por longo } \\
\text { tempo no PSF. }\end{array}$ & Adesão & 5 & 8 & 20 & 70 & 781 & $95,6 \%$ & 884 \\
\hline 5.11 & $\begin{array}{l}\text { Me dou bem com meus colegas } \\
\text { de equipe de PSF. }\end{array}$ & Relacionamento Intra-equipe & 2 & 10 & 4 & 113 & 754 & $95,5 \%$ & 883 \\
\hline 5.1 & Faço aquilo que gosto. & Identidade com a Tarefa & 0 & 11 & 4 & 125 & 741 & $95,3 \%$ & 881 \\
\hline 5.12 & $\begin{array}{l}\text { Minha equipe do PSF realiza } \\
\text { reuniões com regulariedade. }\end{array}$ & Reuniões de equipe & 14 & 25 & 10 & 128 & 703 & $92,1 \%$ & 880 \\
\hline 5.9 & $\begin{array}{l}\text { Na minha equipe do PSF o } \\
\text { paciente é bem atendido. }\end{array}$ & $\begin{array}{l}\text { Qualidade do atendimento } \\
\text { no PSF }\end{array}$ & 2 & 24 & 14 & 227 & 609 & $90,4 \%$ & 876 \\
\hline 5.16 & $\begin{array}{l}\text { Acredito que os resultados dessa } \\
\text { pesquisa serão bem utilizados. }\end{array}$ & Credibilidade da pesquisa & 10 & 13 & 53 & 156 & 648 & $90,3 \%$ & 880 \\
\hline 5.7 & $\begin{array}{l}\text { O trabalho no PSF permite que eu } \\
\text { melhore meus conhecimentos. }\end{array}$ & Crescimento no trabalho & 15 & 35 & 182 & 575 & 518 & $6,9 \%$ & 876 \\
\hline 5.8 & $\begin{array}{l}\text { Considero que os serviços de minha } \\
\text { equipe do PSF possuem qualidade. }\end{array}$ & Qualidade do serviço no setor & or 11 & 27 & 18 & 301 & 522 & $86,9 \%$ & 879 \\
\hline 5.10 & $\begin{array}{l}\text { Os profissionais da equipe do PSF } \\
\text { podem discutir as dificuldades } \\
\text { encontradas no trabalho. }\end{array}$ & $\begin{array}{l}\text { Confiança nas relações } \\
\text { de equipe }\end{array}$ & 28 & 30 & 24 & 227 & 574 & $86,5 \%$ & 883 \\
\hline 5.15 & $\begin{array}{l}\text { Meu trabalho é valorizado pela } \\
\text { comunidade. }\end{array}$ & Imagem externa & 5 & 38 & 33 & 308 & 500 & $85,6 \%$ & 884 \\
\hline 5.13 & $\begin{array}{l}\text { MInha Unidade Básica de Saúde } \\
\text { realiza reuniões com regularidade. }\end{array}$ & Reuniões da unidade & 44 & 45 & 16 & 168 & 606 & $85,5 \%$ & 879 \\
\hline 5.6 & $\begin{array}{l}\text { No PSF, meu potencial e minhas } \\
\text { experiências são utilizados. }\end{array}$ & Uso de habilidades & 15 & 55 & 28 & 295 & 480 & $83,5 \%$ & 873 \\
\hline 5.2 & $\begin{array}{l}\text { O treinamento que recebo é suficiente } \\
\text { para realizar meu trabalho no PSF. }\end{array}$ & Treinamento & 57 & 127 & 25 & 490 & 183 & $67,4 \%$ & 882 \\
\hline 5.4 & $\begin{array}{l}\text { Disponho de materiais para realizar } \\
\text { meu trabalho. }\end{array}$ & Materiais & 86 & 195 & 25 & 405 & 161 & $60,3 \%$ & 872 \\
\hline 5.5 & Sinto muita tensão no trabalho. & Stress & 162 & 343 & 51 & 86 & 239 & $47,1 \%$ & 881 \\
\hline 5.3 & $\begin{array}{l}\text { O ambiente físico da unidade } \\
\text { dificulta meu trabalho. }\end{array}$ & Ambiente físico & 230 & 301 & 39 & 100 & 202 & $42,6 \%$ & 872 \\
\hline
\end{tabular}

Fonte: Coordenação da Atenção Básica e Programa de Saúde da Família - SMS/SP

As respostas espontâneas dos auxiliares de enfermagem às perguntas abertas sobre os aspectos positivos do trabalho no PSF apontaram elementos constitutivos do processo de trabalho e das relações de trabalho, ao mesmo tempo em que revelaram valores culturais e sociais que nos remetem a representações sociais de diferentes 'tempos' de duração 12 na sociedade. Algumas, muito recentes, aparecem quase conjunturalmente, outras têm a duração de uma geração, outras, ainda, ultrapassam várias gerações, permanecendo por um longo período histórico.

A maioria dos sujeitos referiu-se à importância do "reconhecimento" externo, isto é, dos usuários, sobre seu trabalho, seja da parte de pacientes e familiares, seja da 
parte da população atendida ou da comunidade de referência. Mas muitos valorizam também o reconhecimento no interior da instituição, pelos colegas e, especialmente, pelas chefias, quando estas avaliam positivamente o 'empenho' dos entrevistados.

Podemos dizer que este é um indício de certo grau de satisfação dos trabalhadores, tanto com o processo de trabalho, pelo reconhecimento interno e dos superiores, quanto com a avaliação do produto final, pelos usuários.

O tipo de relações que se estabelecem durante o processo de trabalho foi também muito valorizado, com muitas referências ao "trabalho em equipe", ao bom relacionamento com os colegas, com os pacientes, com a população e com a chefia. Muitos apresentam como positivo o fato de "serem ouvidos" na equipe e contarem com o companheirismo dos colegas de trabalho, que muitas vezes se parecem mais com "amigos".

Essas observações nos remetem à percepção da existência de relações mais horizontalizadas e menos hierárquicas no interior das equipes de saúde da família, o que também caracteriza as relações com pacientes e comunidades.

O "vínculo" que se estabelece entre o trabalhador, o usuário e a família também aparece de forma muito freqüente nas respostas, contrapondo-se, de certa forma, aos valores que acompanharam o desenvolvimento do pensamento científico e a profissionalização das ocupações na área de saúde. Defenderam e ainda defendem a importância dos trabalhadores em manterem uma "certa distância" dos pacientes, evitando envolver-se exageradamente com eles, para não perder a "objetividade científica", nem a "perspectiva profissional".

As idéias de "servir", de "ajudar" os que "precisam", a "população carente", apareceram em muitas das respostas, freqüentemente associadas à idéia de que se deve prestar ajuda ao "próximo" e "cuidar dele".

Menções ao processo de trabalho, ao seu ritmo e, especialmente, a alguns instrumentos de trabalho e atividades que fazem parte da proposta foram valorizados, embora tenham aparecido com menor freqüência o "acolhimento" dos usuários nas unidades, o trabalho com grupos de pessoas e comunidades, as visitas domiciliares e o acompanhamento das pessoas acamadas no domicílio. Foi também valorizada a qualidade do atendimento que é possível prestar a partir do processo instaurado, diferentemente de experiências vividas anteriormente pelos entrevistados, especialmente no trabalho em hospitais.

E, por último, houve respostas positivas sobre o trabalho no PSF vinculadas às propostas e aos princípios do SUS, à ação na área de saúde, não apenas centradas na perspectiva de cura das doenças, mas na prevenção, na promoção da saúde e na qualidade de vida.

As respostas sobre os aspectos negativos apontam, em primeiro lugar, para as condições de trabalho, entendidas como "falta de estrutura", "espaço físico inadequado", "falta de medicamentos" e de "profissionais" nas equipes, prin- 
cipalmente de médicos e enfermeiros. Outros aspectos dizem respeito à jornada de trabalho de oito horas diárias, que foi apontada como muito longa, não permitindo que o profissional continue a estudar para melhorar sua formação.

Dentre as insatisfações com as condições de trabalho, apareceram queixas de que o trabalho no PSF é estressante, devido às situações que os profissionais enfrentam diante das dificuldades de acesso da população e de suas condições de vida, o que nos levaria a considerá-lo um trabalho 'penoso'. Mas alguns entrevistados consideram que o trabalho deve ser classificado como 'perigoso' para o profissional, diante das situações de violência que presenciam ou a que estão expostos no dia-a-dia, nas atividades com as famílias ou com a população e até mesmo nas unidades de saúde.

As relações de trabalho foram consideradas por alguns como causadoras da insatisfação no trabalho no PSF: as queixas referem falta de cooperação entre os colegas, falta de compreensão da população, relações conflituosas com a chefia, com médicos, enfermeiros e, às vezes, com o agente comunitário de saúde.

Em terceiro lugar, foram apontados como aspectos negativos no trabalho os problemas na implantação do programa: conflitos nas unidades mistas (PSF e unidades básicas de saúde), não cumprimento das diretrizes por falta de compreensão da equipe ou pelo menos de alguns profissionais. Outros aspectos mencionados foram o uso político do programa, o receio da partidarização e a insegurança com o momento político, pois o questionário foi aplicado muito próximo das eleições municipais.

A insatisfação dos auxiliares de enfermagem com sua formação atual e futura foi bastante citada. Reclamam que se sentem despreparados para o trabalho que devem desenvolver no PSF e que a capacitação recebida de início é insuficiente para enfrentar problemas tão complexos. As condições sociais em que vive a população atendida, sua pobreza, sua carência, a falta de recursos na comunidade, o desinteresse dos usuários também causam insatisfação em alguns dos pesquisados.

Outros motivos de insatisfação apareceram, embora em menor número. Alguns dizem respeito ao processo de trabalho, apontando para o 'desvio de funções', dificuldades para realização das visitas domiciliares e mau atendimento ou despreparo da equipe para realizar o acolhimento dos que procuram a unidade de saúde.

Quando indagados sobre as sugestões que teriam para o PSF na cidade de São Paulo, a grande maioria dos profissionais propôs que o programa fosse ampliado e houvesse diversificação das equipes, incorporando psicólogos e assistentes sociais, mas sempre selecionando profissionais interessados.

Um segundo grupo de respostas, que numericamente corresponde a menos da metade das respostas anteriores, refere-se à necessidade de investimento no profissional, oferecendo-lhe oportunidade de estudo, ajuda de custo, bolsa de estudo - sugestões estas que estão de acordo com as ex- 
pectativas de manter sua formação, como expressam estes profissionais em respostas anteriores. Sugerem que haja capacitação profissional no PSF e, na questão da 'qualificação' para o trabalho, aparecem claramente preocupações com a ética profissional. Há sugestões para treinamentos, cursos profissionalizantes e especialização.

Para melhorar as condições de trabalho, há sugestões sobre espaço físico, aumento salarial, redução da jornada de trabalho, alternativas de várias jornadas de trabalho (não só de 40 horas semanais), melhoria do material para o trabalho, informatização, diminuição da burocracia, pagamento de horas extras, vale-transporte e vale-refeição, "auxílio" para os que trabalham em "áreas de risco", isto é, em áreas em que o grau de violência é maior, e, ainda, a redução da intensidade do trabalho, diminuindo o número de famílias atendidas por cada equipe.

Enquanto alguns sugeriram redução da jornada e outras medidas para ajudar a enfrentar o trabalho, que é muito penoso, outros propuseram o funcionamento da unidade durante 12 horas diárias.

Foi bastante enfocada ainda a questão da referência e contra-referência de pacientes para níveis mais complexos de atenção, a preocupação com a ampliação dos serviços, a reorganização do sistema e a melhoria do nível de informação.

Sugestões foram feitas no sentido de se "resgatar" as diretrizes do PSF, "acabar" com as "unidades mistas", isto é, unidades que têm equipes de PSF e são também unidades básicas de saúde. Na opinião da maioria dos profissionais que citaram esta situação, a experiência tem sido negativa.

\section{Razões para a escolha profissional e para o trabalho no PSF}

Respondendo às questões abertas, as razões mais citadas para a escolha da profissão entre os auxiliares de enfermagem são razões altruístas, tais como "solidariedade", "cuidar" de idosos, crianças, doentes, e razões muito próximas das idéias religiosas ou da caridade cristã, como "amor ao próximo". Às vezes, as respostas aparecem em uma linguagem mais 'atual', revelando também valores altruístas, mas que podem estar mesclados com discursos de caráter mais político ou mais educativo do que de ordem moral, tais como "ajudar" o povo, a população ou a comunidade.

Em seguida, embora com menos da metade da freqüência das anteriores, aparecem razões que denominamos 'pessoais', como a existência de uma "vocação" para a profissão, "ter um dom" para a profissão, ou a realização de um "sonho".

Um terceiro grupo de razões está ligado à história pessoal do entrevistado ou à influência exercida pela família na escolha da profissão, seja pelo 
incentivo ou pelo exemplo, já que muitos têm auxiliares ou enfermeiros na família ou tiveram parentes que exerciam atividades ligadas ao setor informal da saúde ou mesmo à medicina popular. A influência da família na escolha da profissão apareceu também de outra maneira, a partir de experiências com o adoecimento vividas pelo entrevistado, seja no sentido positivo de ter participado do cuidado de parentes próximos, seja por ter passado por experiências negativas de atendimento na área de saúde. De certa forma, as experiências familiares positivas ou negativas puderam direcionar o interesse dos entrevistados pela profissão, tanto para reforçá-la quanto para resgatá-la ou mesmo negá-la.

Foram apontadas também razões ligadas ao mercado de trabalho, tais como oportunidade de emprego, necessidade de trabalhar ou valor do salário a receber. De certa forma, podemos classificar estas razões como 'mais objetivas', dentro das possibilidades de escolha racional para sua inserção social e sobrevivência, já que a área de saúde é um importante setor da economia, que absorve grande parte da mão-de-obra no país. No entanto, as respostas revelam também 'adesão' ao trabalho e à profissão a posteriori, uma vez que alguns sujeitos pretendiam ser enfermeiros ou médicos mas, como sua situação social não permitiu, isso os levou a aderir à profissão 'possível' para eles na área de saúde, que foi a de auxiliar de enfermagem.

Já a razão expressa pelo maior contingente dos entrevistados para optar pelo PSF foi a oportunidade de trabalho, constituindo-se o programa em uma nova alternativa do mercado de trabalho em saúde. Para alguns, foi o primeiro emprego, enquanto profissionais recém-formados. Outros viram no programa a possibilidade de encerrar um período relativamente longo de desemprego na cidade de São Paulo e a perspectiva de contratação no mercado formal, inclusive com certa garantia de estabilidade profissional.

Mas alguns qualificam o PSF não apenas como uma oportunidade de trabalho, mas também como a oportunidade de realizar um trabalho "que é reconhecido", demonstrando que tinham conhecimento do programa, bem como da proposta oferecida aos profissionais, quando decidiram trabalhar nele.

Para um grupo de entrevistados, tornar-se auxiliar de enfermagem no PSF ocorreu por curiosidade; para outros, foi como viver um processo de ascensão na carreira, de agente comunitário de saúde para auxiliar de enfermagem. Para outros, um "acaso", um processo aleatório que aconteceu em suas vidas. Ou, ainda, porque a unidade básica em que trabalhavam passou a organizar-se segundo o PSF. Mas em todos os grupos as respostas sempre ressalvam que, qualquer que tenha sido o motivo inicial, aderiram à proposta posteriormente.

Outras razões indicam também escolhas racionais, como aquelas em que os entrevistados explicam que se voltaram para a profissão no PSF depois 
que passaram por experiências de trabalho na área hospitalar. Cumpre-nos lembrar que, segundo os dados do perfil dos trabalhadores no programa no município de São Paulo, o hospital foi o local de trabalho anterior mais freqüente entre médicos, enfermeiros e auxiliares de enfermagem.

Um terceiro grupo de entrevistados apresentou como razão para ter iniciado o trabalho no PSF o desejo de "servir", "ajudar" e "ser útil", razões de caráter mais altruísta do que utilitário ou de 'aproveitamento de oportunidades'. A possibilidade de ajudar dirige-se a objetos diferenciados: vai desde a ajuda "ao próximo", "à comunidade", "à população carente", até a ajuda "à sociedade". Para alguns deles, o desejo de ajudar foi concretizado pela possibilidade de criar um vínculo do profissional com a comunidade, com a família, a população, o paciente, ou até - como se referem alguns com os "clientes".

Outra parcela de auxiliares de enfermagem respondeu a esta questão argumentando sobre as características do trabalho, afirmando que pode ser desenvolvido junto à comunidade, no atendimento à população através do trabalho em equipe, e que é "diferenciado" e apresenta qualidade. De certa forma, este grupo procurou ressaltar os elementos centrais do trabalho no PSF, especialmente os que apresentam uma conotação positiva.

Outros justificam sua inserção no programa afirmando que ele foi apresentado pela SMS/SP aos funcionários que já trabalhavam nas unidades básicas de saúde e que, por isso, muitos funcionários acabaram aderindo. Não fica claro se esta adesão foi de fato uma adesão ou um certo conformismo para não perder o emprego ou ser transferido para outra unidade de saúde.

\section{Perspectivas para o futuro profissional}

Quando indagados sobre as perspectivas para seu futuro profissional, a resposta mais freqüente dos entrevistados foi que pretendem continuar sua formação, concluindo um curso de nível superior, especialmente de enfermagem, e também cursando especialização em Saúde Pública ou Saúde da Família. Alguns apontaram outros cursos de nível universitário, sendo o de Serviço Social isoladamente o mais citado, embora houvesse referências a outros cursos da área da saúde, tais como Ciências Biológicas, Psicologia, Terapia Ocupacional, Nutrição, Farmácia, Educação Física, Medicina, da área de humanas, como Direito, e também de exatas, como Computação.

A opção por cursar a graduação de Serviço Social pode ser entendida como a possibilidade de se preparar para o enfrentamento dos problemas sociais ou do trabalho com a comunidade, tarefas a serem desenvolvidas para cumprir as diretrizes e o ideário da proposta do PSF. Outro grupo grande de auxiliares de enfermagem não revela expectativas de cursar a universidade, 
mas preocupação com aprimoramento, capacitação, qualificação, treinamento e reciclagem, tendo em vista obter maior conhecimento na área de saúde e melhorar sua formação para melhor atuar no PSF. E ainda encontramos expectativas em torno da formação, mas neste caso de nível técnico, isto é, conseguir concluir o Curso Técnico de Enfermagem como um 'degrau' para chegar à universidade futuramente.

Uma quarta resposta freqüente a respeito dos planos dos auxiliares de enfermagem para seu futuro profissional reflete a intenção de permanecer no PSF e também a expectativa de aposentar-se nesse trabalho. No entanto, outros, mesmo afirmando que querem continuar no PSF, explicitam que gostariam de exercer outra profissão no programa, principalmente a profissão de enfermeiro.

\section{Conclusões}

No caso desta pesquisa, além de descrever o perfil dos auxiliares de enfermagem que integram as equipes de saúde da família na cidade de São Paulo, houve a preocupação em levantar suas opiniões e expectativas, bem como as razões tão diversificadas para a escolha profissional ou pelo PSF.

Esses conhecimentos nos permitem avançar na abordagem da questão dos recursos humanos em saúde, bem como apontam novos conceitos a serem utilizados na análise dos resultados, especialmente nos estudos acadêmicos.

Estudos têm demonstrado que as representações sociais conformam a maneira pelas quais as profissões são percebidas pelos seus membros, os significados que orientam as disposições desses grupos para a ação no campo profissional, as análises e julgamentos que eles expressam sobre a realidade em que vivem, inclusive no trabalho cotidiano, bem como as expectativas que projetam para seu futuro (Ignarra, 2002).

A expressão dos valores de ajuda ao próximo, a quem "precisa", articula-se com representações sociais muito antigas e arraigadas na sociedade, vinculados aos ideais da caridade e da filantropia. Pode-se dizer que resgatam valores caros a diversas religiões e, ao mesmo tempo, são resquícios de uma fase em que a política de saúde ainda não era considerada como um direito de cidadania. O cuidado com o doente, com os socialmente excluídos, apresentado como um dever da caridade, remete-nos a valores e práticas vigentes desde a Idade Média.

A crença no PSF e a permanência nele apresentam-se também como elementos importantes na análise dos dados. A vontade de evoluir na profissão, seja buscando a capacitação ou o aprimoramento, pode ser observada como indício de que pelo menos parte destes profissionais expressa a neces- 
sidade de ampliar e melhorar seu potencial de trabalho, para atuar junto aos segmentos da população assistidos pelo programa.

Por outro lado, este é um potencial a ser considerado pelo gestor, já que muitas das críticas e insatisfações estão centradas na gestão (principalmente de recursos humanos), nas condições de trabalho e nos 'usos indevidos' do PSF. Há, portanto, um potencial real a ser explorado pelo poder público na consecução de sua política social, pois se percebe, ainda que no plano do discurso, a preocupação dos trabalhadores com seu desenvolvimento profissional, com a melhor realização de suas tarefas, através do acesso a várias possibilidades de formação especializada.

E, principalmente, esses trabalhadores apontam a necessidade de 'serem cuidados eles próprios', para suportarem um trabalho que muitas vezes não apresenta o retorno esperado, devido às condições gerais de vida da população ou à ausência de outras políticas setoriais que complementem as ações em saúde.

A situação encontrada demonstra também a necessidade de a administração pública desenvolver programas que permitam a formação técnica desta categoria profissional, para que mais rapidamente sejam cumpridas as exigências legais.

\section{Notas}

1 Professora do Departamento de Medicina Social da Faculdade de Ciências Médicas da Santa Casa de São Paulo e do Programa de Estudos Pós-Graduados em Serviços Sociais. Coordenadora do Núcleo de Estudos e Pesquisa Saúde e Sociedade da Pontifícia Universidade Católica de São Paulo (PUC-SP). Doutora em Ciências Sociais pela Universidade de São Paulo (USP). <reginamarsiglia@ig.com.br>

${ }^{2}$ A pesquisa foi desenvolvida pela equipe de profissionais da Coordenadoria de Atenção Básica da Secretaria Municipal de Saúde de São Paulo, sob orientação da coordenadora Joana Azevedo da Silva, em 2004. A análise foi realizada em 2005, sob a forma de consultoria para o Fundo das Nações Unidas para Educação e Cultura (Unesco), pela equipe da Profa. Regina Giffoni Marsiglia, Dr. Cássio Silveira e Dr. Nivaldo Carneiro Junior (FCMSC/SP), Dr. Paulo Henrique D'Angelo Seixas (CRH/SES/SP). Dra. Joana Azevedo da Silva, técnicos de pesquisa: Denise Perroud Amaral e Marisa Fumiko Nakal (CEALAG-FCMSCSP), Francies Regyane de Oliveira e Vladimir Silva Goldbam (PUCSP).

${ }^{3}$ A lei $n^{0} 7.498 / 86$ procurou readequar a ocupação dos atendentes para a de auxiliares de enfermagem, através da escolarização formal e da formação em serviço, de acordo com os conselhos Regional e Federal de Enfermagem, bem como definiu a constituição das equipes de enfermagem, que em dez anos deveriam estar integradas apenas por enfermeiros, técnicos, auxiliares de enfermagem e parteiros. 
4 Conselho Nacional de Educação, Câmara de Educação Básica (CNE/CEB): os currículos dos cursos médios organizados nas áreas de ciências da natureza e da matemática, linguagem e códigos e ciências humanas constituem a base para a educação profissional de nível técnico (MEC, 1999).

${ }^{5}$ Acompanhando a seqüência das propostas para a formação do pessoal de enfermagem e da Política de Saúde no País podemos constatar: O Projeto Larga Escala na segunda metade dos anos 1970, desenvolveu-se a partir dos Programas de Extensão de Cobertura (PEC) no Brasil, como estratégia de atendimento às necessidades básicas de saúde das populações que não tinham acesso aos serviços. O governo brasileiro assinou com a Organização Pan-Americana da Saúde (Opas) um acordo de cooperação técnica para o desenvolvimento de recursos humanos, dando origem ao Programa de Preparação Estratégica de Pessoal de Saúde (PPREPS) (1976), com o objetivo de promover a formação de pessoal de saúde através do treinamento de pessoal de nível médio e elementar, integração docente-assistencial e criação de Sistemas de Desenvolvimento de recursos humanos para a saúde. Os objetivos do PPREPS estão na base da proposta de formação de pessoal dos níveis médio e elementar, conhecido como Projeto Larga Escala, em 1982, e de enfrentar o desafio de formar pessoal sem tirá-los do trabalho, proposta metodológica baseada na problematização da situação de vida e trabalho dos próprios trabalhadores de saúde (Silva, 2002). Posteriormente, os PEC foram reforçados pelas decisões da Conferência Internacional de Cuidados Primários em Saúde, realizada em 1978, em Alma-Ata, e pela definição do Programa da Interiorização das Ações de Saúde e Saneamento (PIASS), em 1997, com o objetivo de usar amplamente o pessoal auxiliar. Posteriormente, o Profae constituiu-se em outra iniciativa do Ministério da Saúde, através da Secretaria de Gestão de Investimentos em Saúde (SIS), com o objetivo de qualificar os atendentes de enfermagem e dar continuidade à formação dos auxiliares, reforçando as escolas técnicas do SUS, de 2000 a 2003, com recursos do Banco Interamericano de Desenvolvimento (BID), do Tesouro Nacional e do Fundo de Amparo ao Trabalhador (FAT).

${ }^{6}$ Em 2001, a coordenadora de Saúde da Família da Secretaria Municipal de Saúde de São Paulo, Dra. Anna Maria Chiesa, criou uma equipe composta por professores de diversas instituições para elaborar uma proposta de capacitação para os auxiliares de enfermagem no PSF.

7 A proposta de capacitação do auxiliar de enfermagem para o PSF propunha o desenvolvimento de oito competências gerais e quatro específicas para atuação no processo de trabalho em saúde, que foram validadas por enfermeiras e auxiliares de enfermagem que atuavam no Projeto Qualis (Qualidade Integral à Saúde) de 1995 a 2000, nos convênios estabelecidos entre a Secretaria Estadual de Saúde de São Paulo e a Casa de Saúde Santa Marcelina, Fundação Zerbini, Associação Congregação Santa Catarina e Organização Santamarense de Educação e Cultura para implantação de grupos de saúde da família, em parte das zonas Leste, Norte, Sudeste e Sul da cidade de São Paulo, antes da municipalização da atenção básica na cidade (Chiesa et al., 2001, p. 5).

8 O conteúdo do curso de capacitação dos auxiliares de enfermagem para o PSF, com duração de 440 horas, sendo 220 horas de aulas teóricas e 220 horas de aulas e atividades práticas, deveria ser constituído em cinco módulos: 1) Trabalho em saúde: conceitos e concepções; 2) Planejamento e avaliação das ações na Unidade de Saúde da Família; 3) Trabalho do auxiliar de enfermagem no PSF: ciclos de vida; 4) Trabalho do auxiliar de enfermagem: aspectos tecnológicos e instrumentais; e 5) Trabalho do auxiliar de enfermagem: cidadania, ética e humanização (Chiesa et al., 2001, p. 5-6). 
${ }^{9}$ Ver trabalhos sobre o PSF em áreas metropolitanas em: Jatene et al. (1990), Bousquat (2000), Caetano e Dain (2002), Cohn e Bousquat (2003), Elias (2004), Matos (2002), Marques e Mendes (2003), Scorel (2002), Souza e Sampaio (2002), Sena (2002), Viana et al. (2004), Bousquat et al. (2005), Marsiglia et al. (2005) e Cohn et al. (2005).

10 Escala elaborada por Cláudia Valentina de Arruda Campos, mestranda da Fundação Getúlio Vargas, para a SMS/SP, em 2004.

${ }^{11}$ Considera-se, aqui, apenas os resultados mais freqüentes; percebe-se uma distribuição homogênea em três faixas etárias.

12 "Representações sociais", para Minayo (1995, p.89), é um termo filosófico que significa "a reprodução de uma percepção retida na lembrança ou do conteúdo do pensamento". Na abordagem de vários autores das ciências sociais, as representações sociais são explicadas como categorias de pensamento que expressam a realidade, explicam-na, justificando ou questionando-a. Muitas delas atravessam a história, parecendo acompanhar a humanidade em toda sua existência ou pelo menos secularmente, outras acompanham uma ou duas gerações apenas na sociedade, enquanto outras permanecem durante pouco tempo, apenas no presente imediato. Constituem, de certa forma, um pensamento social, que não é necessariamente consciente no indivíduo.

\section{Referências}

AGUDELO, Maria Consuelo C. 1995. El trabajo en enfermería. In: Machado, Maria Helena. (org.). Profissões de saúde: uma abordagem sociológica. Rio de Janeiro: Editora Fiocruz, p. 149-162.

BERNARDINO, Mônica T. S. M. et al. 2005. Consensos e divergências: a capacitação profissional das equipes de saúde da família no Município de São Carlos (SP). Trabalho, Educação e Saúde, v. 3, n. 1, p. 75-89.

BOUSQUAT, Aylene. 2000. Para incorporação do espaço no estudo da saúde. Tese de doutorado, São Paulo: Faculdade de Medicina, Universidade de São Paulo. .COHN, Amélia; ELIAS, Paulo E. 2005. O PSF e a dinâmica urbana nas grandes cidades. In: VIANA, Ana Luiza; ELIAS Paulo E.; IBANËZ, Nelson (orgs.). Proteção social: dilemas e desafios. São Paulo: Hucitec, p. 244-265.

CAETANO, Rosângela; DAIN, Sulamis. 2002. O Programa de Saúde da Família e a reestruturação da atenção básica à saúde nos grandes centros urbanos: velhos problemas, novos desafios. Physis, v. 12, n. 1, p. 11-23.

CARNEIRO JR., Nivaldo; MARSIGLIA, Regina G. 2004. Acesso, acessibilidade e aceitabilidade do Programa Saúde da Família no município de São Paulo. São Paulo: Cedec, Secretaria Municipal de Saúde de São Paulo. (Mimeo).

CHIESA, Anna M. et al. 2001. Capacitação para auxiliares de enfermagem para PSF. São Paulo: Coordenadoria de Saúde da Família, Secretaria Municipal de Saúde de São Paulo. (Mimeo).

COHN, Amélia; BOUSQUAT, Aylene; ELIAS, Paulo E. et al. 2003. Avaliação e construção de indicadores para o monitoramento da implantação do PSF no município de São Paulo. Relatório final da primeira fase da pesquisa para a Fapesp. São Paulo: Secretaria Municipal de Saúde de São Paulo. 
COHN, Amélia; NAKAMURA, Eunice; COHN, Clarice. 2005. O Programa de Saúde da Família entre o público e o privado. In: VIANA, Ana Luiza; ELIAS, Paulo E.; IBANËZ, Nelson (orgs.). Proteção Social: dilemas e desafios. São Paulo: Hucitec, p. 168-185.

DAL POZ, Mário G. S. et al. 1992. Formação de recursos humanos de nível médio em saúde no Rio de Janeiro: a experiência da Escola Técnica em Saúde Enfermeira Izabel dos Santos. Cadernos de Saúde Pública, v. 8, p. 57-61.

ELIAS, Paulo E. et al. 2003. A implantação do Programa de Saúde da Família na metrópole paulista (2001-2003). Revista Brasileira de Saúde da Família, v. 5, n. 7, p. 62-71. Edição especial.

FALCÃO, André. et al. 2003. Observatório de Recursos Humanos em Saúde no Brasil: estudos e análises. Rio de Janeiro: Fundação Oswaldo Cruz.

GIRARDI, Sabado N.; CARVALHO, Cristiana L. 2002. Mercado de trabalho e regulação das profissões de saúde. In: NEGRI, Barjas; FARIA, Regina; VIANNA, Ana Luiza (orgs.). Recursos humanos em saúde: política, desenvolvimento e mercado de trabalho. Campinas: Instituto de Economia, Unicamp.

IGNARRA, Regina Maria. 2002. Medicina: representações de estudantes sobre a profissão. Tese de Doutorado, São Paulo: Faculdade de Saúde Pública, Universidade de São Paulo.

JATENE, Adib D. et al. 1999. Novos modelos de assistência à saúde: avaliação do PSF/Qualis no município de São Paulo. Relatório de Pesquisa. São Paulo: Faculdade de Medicina, Universidade de São Paulo/Faculdade de Ciências Médicas da Santa Casa de São Paulo.

MACHADO, Maria Helena (org.). 1995. Profissões de saúde: uma abordagem sociológica. Rio de Janeiro: Editora Fiocruz. .2000. Perfil dos médicos e enfermeiros do PSF no Brasil: relatório final. Brasília: Ministério da Saúde. (v. 1, Brasil e Grandes Regiões).

MARCONI, Marina A.; LAKATOS, Eva M. 1986. Técnicas de pesquisa. São Paulo: Atlas.
MARQUES, Rosa M.; MENDES, Áquilas. 2003. Atenção básica e Programa da Saúde da Família (PSF): novos rumos para a política de saúde e seu financiamento? Ciência e Saúde Coletiva, v. 8, n. 2, p. 393-401.

MEC (Ministério da Educação). 1999. Resolução no. 4, de 8 de novembro de 1999. Institui as Diretrizes Curriculares Nacionais para a Educação Profissional de Nível Técnico. Brasília: Câmara de Educação Básica.

MINAYO, Maria Cecília de S. 1995. O conceito de representações sociais dentro da sociologia clássica. In: GUARESCHI, Paulo; JOVCHELOVITCH, Sandra (orgs.). Textos em representações sociais. $2^{\text {a }}$ ed. Petrópolis, RJ: Vozes, p. 89-111.

MOURA. Maria Lúcia P. de A. et al. 1996. A força de trabalho em enfermagem no Estado de São Paulo. São Paulo: Conselho Regional de Enfermagem de São Paulo/ Associação Brasileira de Enfermagem, Seção São Paulo.

MS (Ministério da Saúde). Secretaria de Assistência à Saúde. 1997. Saúde da Família: uma estratégia para a reorganização do modelo assistencial. Brasília: MS.

MTE (Ministério do Trabalho e Emprego). 1996a. Relação Anual de Informações Sociais (Rais). Anuário Estatístico.

.1996b. Cadastro Geral dos Empregados e Desempregados (Caged). Anuário Estatístico.

NEGRI, Barjas; FARIA, Regina; VIANNA, Ana Luiza (orgs.). 2002. Recursos humanos em saúde: política, desenvolvimento e mercado de trabalho. Campinas, SP: Instituto de Economia, Unicamp.

NOGUEIRA, Roberto P. 1987a. A força de trabalho em saúde no contexto da Reforma Sanitária. Cadernos de Saúde Pública, v. 3, p. 332-342.

.1987b. Tendencias generales del mercado de trabajo médico en las Américas. Revista Brasileira de Educação Médica, v. 11, n. 2, p. 63-65.

OTAVIANO, Jussara. 2005. O auxiliar de enfermagem e as novas solicitações do trabalho no campo da saúde pública: o papel da educação permanente. Dissertação de Mestrado, São Paulo: Curso de 
Enfermagem, Universidade Bandeirante de São Paulo.

PIERANTONI, Célia Regina. 2002. Recursos humanos e gerência no SUS. In: NEGRI, Barjas; VIANA, Ana Luiza (orgs.). $O$ sistema único de saúde em dez anos de desafio: o passo a passo de uma reforma que alarga o desenvolvimento e estreita a desigualdade social. São Paulo: Sobravime/Cealag, p. 609-630.

SCOREL, Sarah; GIOVANELLA, Lígia. 2002. Estratégias de implantação do PSF em grandes centros urbanos. Ciência e Saúde Coletiva, v. 8, p. 130. Suplemento 1.

SENNA, Mônica C. M. 2002. Eqüidade e política de saúde: algumas reflexões sobre o Programa Saúde da Família. Cadernos de Saúde Pública, v. 18, p. 203-11.

SILVA, Joana A.; DALMASO, Ana Silva W. 2002a. Agente comunitário de saúde: o ser, o saber, o fazer. Rio de Janeiro: Editora Fiocruz.

.2002b. O agente comunitário de saúde e suas atribuições: os desafios para os processos de formação de recursos hu- manos em saúde. Interface, v. 6, n. 10, p. 75-83.

SILVA, Joana A. 2002. Estratégias de qualificação e inserção de trabalhadores de nível médio na área da saúde. In: NEGRI, Barjas; FARIA, Regina; VIANA, Ana Luiza (orgs.). Recursos humanos em saúde: política, desenvolvimento e mercado de trabalho. Campinas: Instituto de Economia, Unicamp, p. 373-401.

SINAIS de mercado de trabalho do pessoal de enfermagem no Brasil. 2001. Formação, v. 1, n. 1, p. 47-72.

SOUZA, Heloiza M.; SAMPAIO, Luiz F. R. 2002. Atenção básica: política, diretrizes e modelos coetâneos no Brasil. In: NEGRI, Barjas; FARIA, Regina; VIANA, Ana Luiza (orgs.). Recursos humanos em saúde: política, desenvolvimento e mercado de trabalho. Campinas: Instituto de Economia, Unicamp, p. 9-32.

VIANA, Ana L. et al. 2002. Indicadores de monitoramento da implantação do PSF em grandes centros urbanos. Disponível em: $<$ dtn2002.saude.gov.br/ascom/indicadorespsf $>$. Acesso em: 15 dez. 2004.

Recebido em 30/11/2005

Aprovado em 16/02/2006 